\title{
Reliability on ProSHAKE 2.0 in the Assessment of One Dimensional Ground Response Analysis through Verification Example
}

\author{
PL. Meyyappan
}

\begin{abstract}
It is understood from the recent destructive earthquakes, topography, nature of the bedrock and geometry of the soil deposits are the prime factors that made modifications to the underlying earthquake motion. The influence of such confined soil states on the strong earthquake motion plays a significant task in accessing the uniqueness of ground action. In this paper, the response of the soil layers to the earthquake action of the bedrock directly under it is determined. The analysis is done through frequency domain approach. Pro-shake software 2.0 is used to arrive the reliability of the ground response study. A wide variety of output parameters such as time histories of acceleration, velocity, displacement, shear stress, shear strain, response spectra and maximum amplitude of various parameters with depth are plotted and the other scalar parameters such as peak acceleration, peak velocity, peak displacement, RMS acceleration, arias intensity, predominant period and bracketed duration was computed.
\end{abstract}

Keywords :Earthquakes, Soil Deposits, ProSHAKE, Ground response.

\section{INTRODUCTION}

The assessment of ground response is the most significant and usual predominant issues in the field of geotechnical earthquake engineering. Ground response analysis is been exercised to forecast the ground surface motions for enlargement of design response spectra, to assess dynamic stresses and strains for the assessment of liquefaction threats and to establish the earthquake-stimulated forces that can unswerving to an unsteadiness conditions of earth and earth-retaining structures.Under these idyllic circumstances, a whole ground response analysis would examine the failure mechanism at the source of an earthquake, the dissemination of seismic waves penetrating the earth to the apex of solid rock below a specific site, and would then verify the surface nature of the ground movement is dominant by the soils that stretch out on top of the bedrock.

\section{ONE DIMENSIONAL GROUND RESPONSE ANALYSIS}

One-dimensional wave spread analyses are broadly used for "ground response analysis" or "soil amplification studies" since they are considered to afford some

Revised Manuscript Received on December 05, 2019.

* Correspondence Author

PL. Meyyappan*, Civil department, Kalasalingam Academy of Research and Education, Krishnankoil, India. Email: meyyappan@klu.ac.in conventional outcomes and a huge number of commercial programs with diverse soil models are obtainable. The term one-dimensional refers to the hypothesis that the soil profile enlarges to perpetuity in all the horizontal directions and the base layer is believed a half space. In this category of analysis, only the erect propagation of seismic waves can be considered, typically shear waves. The assumptions made in the 1-D ground response analysis are soil stratums horizontal and expand to perpetuity, the ground face is plane and the occurrence earthquake motions are spatially consistent, horizontally polarized shear waves and disseminate in vertical manner. Various techniques are there for proceeding 'ground response analysis'. All these methods are deviated to one another and based on the narrow down of assumptions that are concern, illustration of stress-strain dealings of soil and in the formats of integration process. The techniques are extensively clustered as three types such as linear analysis, equivalent analysis and non-linear analysis and the evaluation of one dimensional analysis is done by various packages such as SHAKE, DEEPSOIL,EDUSHAKE, PROSHAKE, Cyber Quake, EERA etc. Among the all Pro-Shake, program is having more flexibility and versatility in accessing the uncertainty condition in a seismic site response.

\section{PRO-SHAKE}

ProSHAKE is a free computer program for evaluating earthquake ground response analysis of leveled stratum of soil deposits developed by Edu Pro Civil Systems, Inc., from Sammamish, Washington, U.S.A. The equivalent linear mode of ProSHAKE work outs the ground response in the frequency domain. By using a Fast Fourier Tranform (FFT) the input motion from the time domain is converted to the frequency domain. ProSHAKE represents that motion as the summation of a sequence of sine waves of various amplitudes, frequencies and phase angles. The FFT is a very capable method that involves the total number of acceleration values to be integer power of 2 , allowing up to $2^{14}(16,348)$ terms of motion. The principle of superposition used by ProSHAKE to characterize the motion by means of a fourier series and transfer functions can be valid only for linear systems.

ProShake is categorized into 3groups of "managers" -namely an Input Manager (IM), a Solution Manager (SM), and an Output Manager (OM). The IM grouppermits the access of soil layer and input seismic activity data. The SM group executes an utterance counterpart of linear analysis whereas trailing the practice of meeting towards strain-attuned soil behavior.

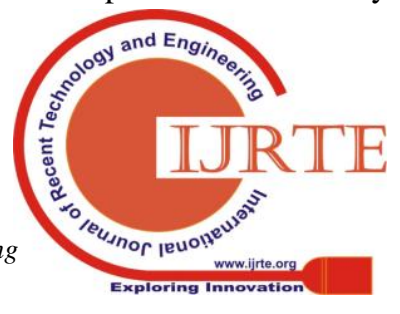


The OM groupallocatesan uncomplicated scheming of end outcomes in the variety of time histories, response spectra, parameter outlines, and simulations. The following flow chart will describes the assessment process of one dimensional ground response analysis using ProShake.

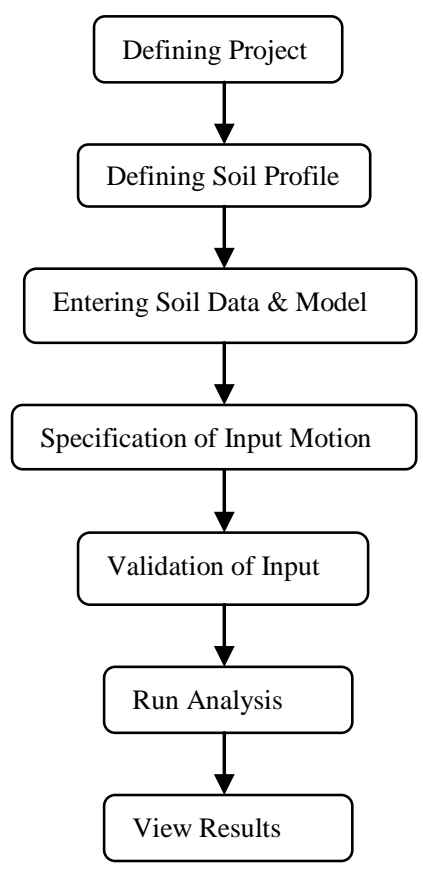

Fig. 1.Example of a figure caption.

Figure 2 describes the process of entering soil data and model through soil model button and therby it permits the built-in models for various profile layers in the ProShake. Through Add key on the base of the soil representations form allocates the assesser to describe an other new soil representations that will consequently emerge with the further soil representations in a drop-down list in the IM group.

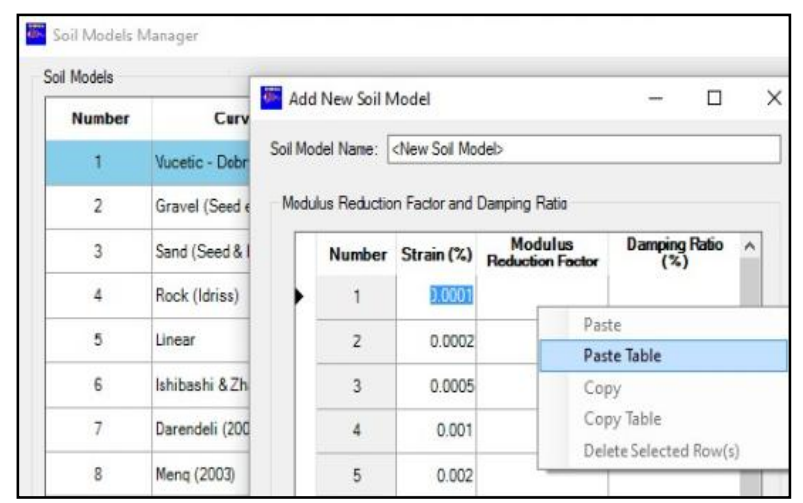

Fig. 2. Snapshot of soil data \& Model in ProShake

\section{VERIFICATION EXAMPLE}

The response of the soil layeris revealed in figure5, when focused to a solid rock seismic activitysimilar to that witnessed at 1940 E L Centro EQ. The soil layer consists of a $15 \mathrm{~m}$ broad layer of soft silty clay in excess of a $15 \mathrm{~m}$ thick layer of stiff clay underlain by solid rock. Its input motion is to be applied on the top of solid rock.

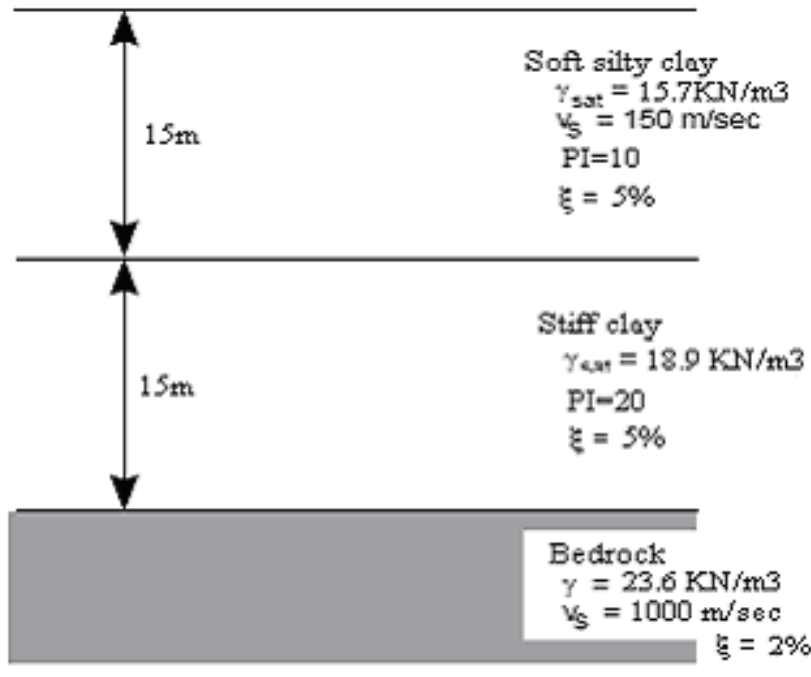

Fig. 3. Soil Profile Diagram

In order to solve the above example in ProShake computer program, the preliminary step is to define number of layers in considering the depth of the bed rock. For this problem, $30 \mathrm{~m}$ depth is taken in to 11 layers including 5 layers for soft silty clay zone, 5 layers for stiff clay zone and 1 layer for bed rock. Except bed rock all the soil layers are equally taken as $3 \mathrm{~m}$. The unit weight of soft silty clay and stiff clay is taken as 15.7 $\mathrm{kN} / \mathrm{m} 3$ and $18.9 \mathrm{kN} / \mathrm{m} 3$ respectively. For bed rock, it is constantly taken as $23.6 \mathrm{kN} / \mathrm{m} 3$. After defining soil profile, soil data is to be entered as layer wise. The soil data should have the details of each layer's name, thickness, unit weight, Gmax, Vmax, modulus decline curve, damping curve and damping factor. The maxium shear modulus and shear velocity is varying from 36 to $390.3 \mathrm{Mpa}$ and $150 \mathrm{~m} / \mathrm{sec}$ to $1000 \mathrm{~m} / \mathrm{sec}$ respectively in according with the depth of soil profile layers. For bed rock, the maximum shear modulus and shear velocity is taken as $2406.5 \mathrm{Mpa}$ and $1000 \mathrm{~m} / \mathrm{sec}$ respectively. Select the in-built curves of modulus reduction and damping which is representing the performance as a role of plasticity index (PI), overconsolidation ratio (OCR), count of loading cycles, and occurrence. Once all the data for soil layers are entered as mentioned in Table 1, then specify the input motion as EL Centro motion as given in the statement of the problem. In order to validate, a rapid confirmation of the input statistics about any omitted or errors has to be performed. Then ProShake computer program has to be execute analysis function for viewing the output results.

\section{RESULT AND DISCUSSION}

Table 2 shows the outcomes of the ground response analysis for the verification example. Fig 4 to 6 shows the output graphical representation of the soil layer 1 and layer 11 for the various responses (Acceleration, Velocity and Displacement) w.r.t time. During the earthquake motion, the bed rock is subjected to a peak acceleration of $0.157 \mathrm{~g}$ but it takes 2.64 times much faster approach in reaching top of the soil layer (Soft stilty clay) with a peak acceleration of 0.415 g. The earthquake motion travels in a velocity of $0.329 \mathrm{~m} / \mathrm{sec}$ in the bed rock and shift to a velocity at the accelerated rate of $0.563 \mathrm{~m} / \mathrm{sec}$ as penetrated in the clay profile layer. The peak displacement observed is $0.119 \mathrm{~m}$ and $0.166 \mathrm{~m}$ for bed rock layer and clay layer respectively. 
Table- II: Soil Profile Data (Input)

\begin{tabular}{|c|c|c|c|c|c|c|c|c|}
\hline $\begin{array}{l}\text { Layer } \\
\text { No }\end{array}$ & $\begin{array}{l}\text { Material } \\
\text { Name }\end{array}$ & $\begin{array}{c}\text { Thickness } \\
\text { (m) }\end{array}$ & $\begin{array}{c}\text { Unit } \\
\text { weight } \\
(\mathrm{kN} / \mathrm{m} 3)\end{array}$ & $\begin{array}{c}\mathrm{G}_{\max } \\
(\mathrm{Mpa})\end{array}$ & $\begin{array}{c}\mathrm{V}_{\mathrm{s}} \\
(\mathrm{m} / \mathrm{s})\end{array}$ & $\begin{array}{c}\text { Modulus } \\
\text { Decline } \\
\text { Curve }\end{array}$ & $\begin{array}{c}\text { Damping } \\
\text { curve }\end{array}$ & $\begin{array}{l}\text { Damping } \\
\text { Factor (\%) }\end{array}$ \\
\hline 1 & $\begin{array}{l}\text { Soft silty } \\
\text { clay }\end{array}$ & 3.0 & 15.7 & 36 & 150 & $\begin{array}{c}\text { Clay-PI=10 } \\
\text { (Sun et al) }\end{array}$ & $\begin{array}{c}\text { Clay-Avg } \\
\text { (Idriss 1990) }\end{array}$ & 5 \\
\hline 2 & $\begin{array}{c}\text { Soft silty } \\
\text { clay }\end{array}$ & 3.0 & 15.7 & 36 & 150 & $\begin{array}{c}\text { Clay-PI=10 } \\
\text { (Sun et al) }\end{array}$ & $\begin{array}{c}\text { Clay-Avg } \\
\text { (Idriss 1990) }\end{array}$ & 5 \\
\hline 3 & $\begin{array}{l}\text { Soft silty } \\
\text { clay }\end{array}$ & 3.0 & 15.7 & 64 & 200 & $\begin{array}{c}\text { Clay-PI=10 } \\
\text { (Sun et al) }\end{array}$ & $\begin{array}{c}\text { Clay-Avg } \\
\text { (Idriss 1990) }\end{array}$ & 5 \\
\hline 4 & $\begin{array}{l}\text { Soft silty } \\
\text { clay }\end{array}$ & 3.0 & 15.7 & 64 & 200 & $\begin{array}{c}\text { Clay-PI=10 } \\
\text { (Sun et al) }\end{array}$ & $\begin{array}{c}\text { Clay-Avg } \\
\text { (Idriss 1990) }\end{array}$ & 5 \\
\hline 5 & $\begin{array}{l}\text { Soft silty } \\
\text { clay }\end{array}$ & 3.0 & 15.7 & 64 & 200 & $\begin{array}{c}\text { Clay-PI=10 } \\
\text { (Sun et al) }\end{array}$ & $\begin{array}{c}\text { Clay-Avg } \\
\text { (Idriss 1990) }\end{array}$ & 5 \\
\hline 6 & Stiff clay & 3.0 & 18.9 & 173.5 & 300 & $\begin{array}{c}\text { Clay-PI=20 } \\
\text { (Sun et al) }\end{array}$ & $\begin{array}{c}\text { Clay-Avg } \\
\text { (Idriss 1990) }\end{array}$ & 5 \\
\hline 7 & Stiff clay & 3.0 & 18.9 & 173.5 & 300 & $\begin{array}{c}\text { Clay-PI=20 } \\
\text { (Sun et al) }\end{array}$ & $\begin{array}{c}\text { Clay-Avg } \\
\text { (Idriss 1990) }\end{array}$ & 5 \\
\hline 8 & Stiff clay & 3.0 & 18.9 & 173.5 & 450 & $\begin{array}{c}\text { Clay-PI=20 } \\
\text { (Sun et al) }\end{array}$ & $\begin{array}{c}\text { Clay-Avg } \\
\text { (Idriss 1990) }\end{array}$ & 5 \\
\hline 9 & Stiff clay & 3.0 & 18.9 & 390.3 & 450 & $\begin{array}{c}\text { Clay-PI=20 } \\
\text { (Sun et al) }\end{array}$ & $\begin{array}{c}\text { Clay-Avg } \\
\text { (Idriss 1990) }\end{array}$ & 5 \\
\hline 10 & Stiff clay & 3.0 & 18.9 & 390.3 & 1000 & $\begin{array}{c}\text { Clay-PI=20 } \\
\text { (Sun et al) }\end{array}$ & $\begin{array}{c}\text { Clay-Avg } \\
\text { (Idriss 1990) }\end{array}$ & 5 \\
\hline 11 & Rock & Infinite & 23.6 & 2406.5 & 1000 & Rock & Rock & 2 \\
\hline
\end{tabular}

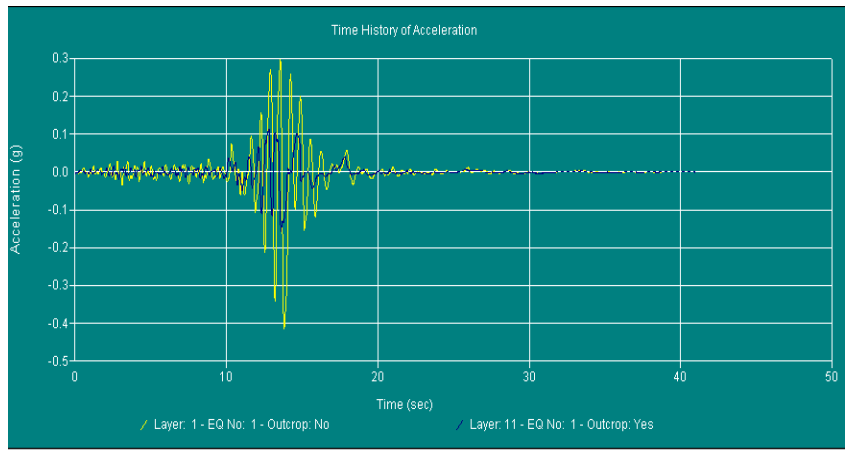

Fig. 4. Acceleration vs Time for Layer 1 and Layer 11

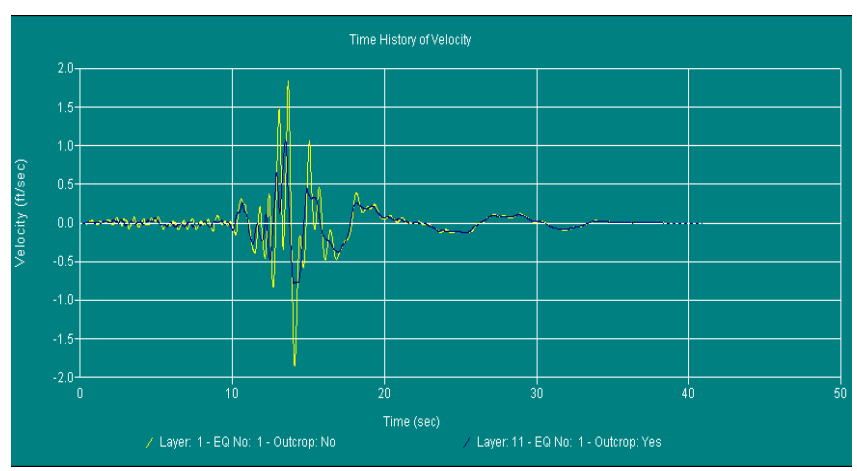

Fig. 5. Velocity vs Time for Layer 1 and Layer 11

The strength of a ground motion is measured by a term called Arias Intensity $\left(\mathrm{I}_{\mathrm{A}}\right)$. This gives an idea of intensity shaking by quantifying the acceleration of transitory seismic waves. It has been identified that, it is a dependable parameter to illustrate the earthquake shaking is obligatory to prompt the possibility of landslides. It is found that the possibility of landslides is large in top layer $(2.008 \mathrm{~m} / \mathrm{sec})$. For this problem, the predominant period is almost same for the bed rock and top layer. This predominant period is necessary for the engineers to design the buildings without any possibility of any damage.

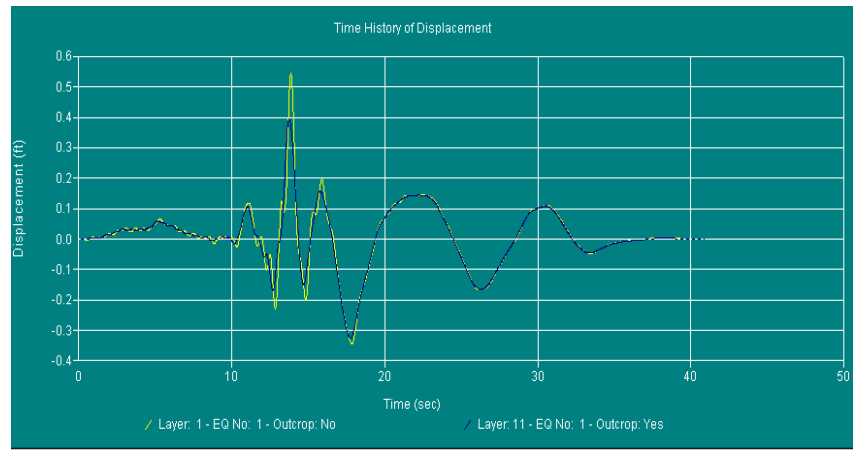

Fig. 6.Displacement vs Time for Layer 1 and Layer 11

Table- II:Ground response analysis results

\begin{tabular}{|c|c|c|}
\hline Output results & Layer 1 & Layer 11 \\
\hline Peak acceleration $(\mathrm{g})$ & 0.415 & 0.157 \\
\hline Peak velocity (m/sec) & 0.563 & 0.329 \\
\hline Peak displacement (m) & 0.166 & 0.119 \\
\hline RMS Acceleration (g) & 0.195 & 0.068 \\
\hline Arias Intensity $(\mathrm{m} / \mathrm{sec})$ & 2.008 & 0.351 \\
\hline Response spectrum intensity $\left(\mathrm{g}^{2}\right)$ & 5.591 & 3.175 \\
\hline Predominant period $(\mathrm{Sec})$ & 0.650 & 0.640 \\
\hline Mean period (sec) & 0.784 & 1.131 \\
\hline Bracketed duration $(\mathrm{sec})$ & 7.700 & 2.780 \\
\hline Trifunac duration $(\mathrm{sec})$ & 3.100 & 4.420 \\
\hline Spectral acceleration at $0.3 \mathrm{sec}(\mathrm{g})$ & 0.841 & 0.426 \\
\hline
\end{tabular}


The damage on the buildings can be prevented by assuring that the fundamental period of the structure doesnot agreed with this predominat time of the seismic activity. The mean period obtained is $0.784 \mathrm{~s}$ which is 1.32 times higher than the 2001 bhuj earthquake goundmotion $(0.59 \mathrm{~s})$.

\section{CONCLUSIONS}

1. Ground response analysis for the verification problem is carried out to determine the various responses of the soil deposits by using Pro-shake program and this program is user friendly and having high reliability in accessing outputs.

2. It is appeared that peak acceleration, peak velocity and peak displacement is higher in soft stilty clay layer than bed rock layer due to the faster movement of earthquake motion in the top layer without the interference of any obstructing medium.

3. In ground response analysis, the predominant period is very essential factor for the engineers to design the structures without any possibility of damage. It should not coincide with the natural time period of the structure.

\section{REFERENCES}

1. ProSHAKE - User Manual, Version 2, Edu Pro Civil Systems, Inc, Washington

2. Z.M. Lindung, S. Likitlersuang and T. Tobita, "Analysis of seismic ground response caused during strong earthquake in Northern Thailand", Soil Dynamics and Earthquake Engineering, Vol.114, Pages 113-126, 2018.

3. Idriss, I.M. and Sun, J.I. (1992). "SHAKE91: A computer program for conducting equivalent linear seismic response analyses of horizontally layered soil deposits," User's Guide, University of California, Davis,

4. California, 13 pp. Ishibashi, I. (1992). Discussion to "Effect of soil plasticity on cyclic response," by M. Vucetic and R. Dobry, Journal of Geotechnical Engineering, ASCE, Vol. 118, No. 5, pp. 830-832.

5. Kramer, S.L. (1996). Geotechnical Earthquake Engineering, Prentice Hall, Upper Saddle River, New Jersey, 653 pp.

6. Ishibashi, I. (1992). Discussion to "Effect of soil plasticity on cyclic response," by M. Vucetic and R. Dobry, Journal of Geotechnical Engineering, ASCE, Vol. 118, No. 5, pp. 830-832.

\section{AUTHORS PROFILE}

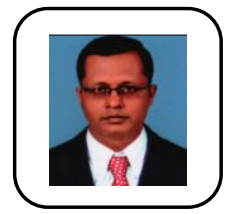

Dr. PL. Meyyappanhas completed his graduation and post-graduation from Bharathiyar University and Karunya University respectively. He completed his $\mathrm{PhD}$ from Kalasalingam University. He has 13 years of teaching experience. He has completed 2 sponsored research projects from TNSCST and published more than 25 papers in peer reviewed journals and conferences. He is a life member in ISTE, IEI, IGS, ISET, ISRS. He is serving as Editorial Board Member and Reviewer in various reputed Journals. 